\title{
Oxytocin reduces adipose tissue inflammation in obese mice
}

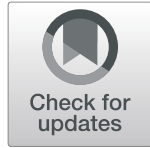

Angela Szeto ${ }^{1}$, Monia Cecati ${ }^{2}$, Raisa Ahmed ${ }^{1}$, Philip M. McCabe ${ }^{1}$ and Armando J. Mendez ${ }^{2^{*}}$ (D)

\begin{abstract}
Background: Obesity and adipose tissue expansion is characterized by a chronic state of systemic inflammation that contributes to disease. The neuropeptide, oxytocin, working through its receptor has been shown to attenuate inflammation in sepsis, wound healing, and cardiovascular disease. The current study examined the effects of chronic oxytocin infusions on adipose tissue inflammation in a murine model of obesity, the leptin receptordeficient $(\mathrm{db} / \mathrm{db})$ mouse.

Methods: The effect of obesity on oxytocin receptor protein and mRNA expression in adipose tissue was evaluated by Western blotting and real-time polymerase chain reaction. Mice were implanted with osmotic minipumps filled with oxytocin or vehicle for 8 weeks. At study endpoint adipose tissue inflammation was assessed by measurement of cytokine and adipokine mRNA tissue levels, adipocyte size and macrophage infiltration via histopathology, and plasma levels of adiponectin and serum amyloid $A$ as markers of systemic inflammation.

Results: The expression of adipose tissue oxytocin receptor was increased in obese $\mathrm{db} / \mathrm{db}$ mice compared to lean controls. In adipose tissue oxytocin infusion reduced adipocyte size, macrophage infiltration, IL-6 and TNFa mRNA expression, and increased the expression of the anti-inflammatory adipokine, adiponectin. In plasma, oxytocin infusion reduced the level of serum amyloid A, a marker of systemic inflammation, and increased circulating adiponectin.
\end{abstract}

Conclusions: In an animal model of obesity and diabetes chronic oxytocin treatment led to a reduction in visceral adipose tissue inflammation and plasma markers of systemic inflammation, which may play a role in disease progression.

Keywords: Adipose tissue, Anti-inflammation, Obesity, Oxytocin, Obese mouse model

\section{Background}

It has been suggested that obesity is characterized by a chronic state of systemic inflammation [1] that contributes to insulin resistance, dyslipidemia, diabetes and cardiovascular disease [2]. Obesity is accompanied by proliferation of adipose tissue [3] which consists of adipocytes, macrophages, fibroblasts, mesenchymal cells, pre-adipocytes, and endothelial cells [4]. Obesity-related

\footnotetext{
* Correspondence: amendez2@med.miami.edu

${ }^{2}$ Department of Medicine and Diabetes Research Institute, University of Miami Miller School of Medicine, 1450 N.W. 10th Avenue, Miami, FL 33136, USA

Full list of author information is available at the end of the article
}

inflammation is thought to be largely due to increased adipose tissue volume, infiltration of monocytes that differentiate into macrophages and express the classical M1 proinflammatory phenotype, and the subsequent secretion of pro-inflammatory cytokines and adipokines from adipocytes and macrophages [5]. It has been demonstrated that visceral adipose tissue, relative to subcutaneous fat, exhibits a greater inflammatory response as a consequence of obesity, evidenced by increased immune cell infiltration and cytokine production [6].

Oxytocin (OXT) is a neuropeptide that has been widely studied in terms of reproduction and social behavior, but more recently has gained attention for its

(c) The Author(s). 2020 Open Access This article is licensed under a Creative Commons Attribution 4.0 International License, which permits use, sharing, adaptation, distribution and reproduction in any medium or format, as long as you give appropriate credit to the original author(s) and the source, provide a link to the Creative Commons licence, and indicate if changes were made. The images or other third party material in this article are included in the article's Creative Commons licence, unless indicated otherwise in a credit line to the material. If material is not included in the article's Creative Commons licence and your intended use is not permitted by statutory regulation or exceeds the permitted use, you will need to obtain permission directly from the copyright holder. To view a copy of this licence, visit http://creativecommons.org/licenses/by/4.0/. The Creative Commons Public Domain Dedication waiver (http://creativecommons.org/publicdomain/zero/1.0/) applies to the data made available in this article, unless otherwise stated in a credit line to the data. 
anti-inflammatory properties. In wound healing and sepsis-induced animal models, subcutaneous injections of OXT were shown to diminish the immune and inflammatory response [7-9]. In our laboratory, we showed that macrophage OXT receptor (OXTR) expression is dramatically upregulated in response to inflammatory stimuli, suggesting that OXTR is an acute-phase protein that likely contributes to the anti-inflammatory actions of OXT [10]. We also demonstrated that chronic subcutaneous OXT infusions in apolipoprotein $\mathrm{E}$ knockout mice attenuated inflammatory atherosclerotic disease and the secretion of IL-6 from visceral adipose tissue [11]. Similarly, OXT infusions in the dyslipidemic Watanabe heritable hyperlipidemic rabbit slowed the progression of atherosclerosis and decreased plasma C-reactive protein levels, a biomarker of systemic inflammation [12]. Given that adipocytes and macrophages express OXTRs [10, 13], it is likely that adipose tissue represents an important target for the antiinflammatory actions of OXT.

There is a growing literature that suggests OXT and its receptor may play an important role in regulating body weight and metabolism. For example, OXTR and OXT deficient mice exhibit late onset obesity and insulin resistance $[14,15]$. In rodent models of obesity, chronic central or peripheral infusions of OXT have been shown to decrease weight gain [16-20] and improve insulin resistance $[18,20,21]$. These effects of OXT are at least partially due to central effects that decrease food consumption and increase energy expenditure [16-19].

The current study examined the effects of chronic OXT infusions on adipose tissue inflammation in a murine model of obesity and diabetes, the leptin receptor-deficient $(\mathrm{db} / \mathrm{db})$ mouse. It was hypothesized that the increased inflammation due to adipose tissue expansion in obesity would be attenuated by chronic OXT infusion. Inflammation was assessed by measuring macrophage infiltration into the visceral adipose tissue, as well as tissue expression and plasma levels of cytokines and adipokines. Our data show that OXTR expression is increased in adipose tissue of obese mice, and that OXT infusion attenuated adipose tissue inflammation. These data suggest a role for the OXT/OXTR pathway in peripheral tissue inflammation, and the potential use of OXT, or OXTR agonists, for the treatment of inflammatory disorders related to obesity.

\section{Methods}

\section{Animal subjects}

Mice were obtained from the Jackson Laboratory (Bar Harbor, ME, USA). Male C57BLKS/J Lepr ${ }^{\mathrm{db}-/-}$ (db/db; Stock no. 000642) mice (leptin receptor deficient) and heterozygotes C57BLKS/J Lepr ${ }^{\mathrm{db}-/+}$ (Stock no. 000662) having normal body weight, blood glucose, and plasma insulin served as lean controls. Although there are subtle differences in the magnitude of the inflammatory response among the various mouse models of obesity (e.g., DIO, ob/ob, db/db, agouti and tubby), it has been concluded that adipose tissue inflammation is a general phenomenon of the obese state [22] and therefore is present in all of these mouse models. The $\mathrm{db} / \mathrm{db}$ mouse was chosen because it is a widely used model of obesity and diabetes $[23,24]$ without the concerns associated with the use of high fat diets [25]. The $\mathrm{db} / \mathrm{db}$ mouse is characterized by an obese phenotype and exhibits many of the metabolic aberrations seen in human obesity, including insulin resistance, hyperglycemia and increased inflammation [23, 26, 27].

Although it is important to examine gender differences in obesity and inflammation, it has been shown that both OXT and OXTR expression vary significantly during the estrus cycle [28]. Therefore, in order to simplify the current study, we chose to focus on male mice, however, future studies in female are warranted.

Animals were housed 4 or 5 per cage at $22^{\circ} \mathrm{C}$ on a 12 : $12 \mathrm{~h}$ day-night cycle and fed a normal chow diet (Rodent Chow 5001, LabDiet, Orlando, FL, USA) ad libitum. Mice were received at 6 weeks of age, were acclimated for 1 week, and then randomly assigned to a treatment group the following week and studies initiated when mice were 8 weeks of age. Ten mice per group were studied for the vehicle control and OXT treatment groups (see below), however, two mice in the control group did not complete the study (both due to surgical wounds from pump surgery that did not heal). Procedures for the care, use and euthanasia of experimental animals followed the protocols and regulations set forth by the Animal Care and Use Committee of the University of Miami and conformed to the Guide for the Care and Use of Laboratory Animals published by the US National Institutes of Health.

\section{Isolation of adipocytes and stromal vascular cells from adipose tissue}

Epididymal adipose tissue was removed from lean control and $\mathrm{db} / \mathrm{db}$ mice, minced, and digested using $2 \mathrm{mg} /$ $\mathrm{ml}$ of collagenase type I (Sigma, St. Louis, MO, USA) in Hank's balanced salt solution (HBSS) supplemented with $5.5 \mathrm{mM}$ glucose, $15 \mathrm{mM}$ HEPES, $100 \mathrm{mM}$ sodium pyruvate, $1 \%$ bovine serum albumin, and $200 \mathrm{nM}$ adenosine at $37^{\circ} \mathrm{C}$ in a shaking water bath for $1 \mathrm{~h}$. Tissue digests were filtered through $300 \mu \mathrm{m}$ nylon cell strainers and adipocytes were separated by centrifugation (300 x g for $1 \mathrm{~min}$ ), washed twice with PBS, and used for RNA extraction (below). The pelleted stromal vascular fraction (SVF) cells were treated with red blood cell lysis buffer for $5 \mathrm{~min}$ at room temperature, washed with PBS, centrifuged, and the SVF pellet was used for RNA extraction. 


\section{Osmotic Minipumps and surgeries}

Osmotic minipumps (Alzet model 1004, infusion rates of $0.11 \mu \mathrm{l} / \mathrm{h}$, DURECT Corporation, Cupertino, CA, USA) were filled following manufacturer's guidelines with $0.1 \mathrm{ml}$ vehicle $(50 \mathrm{mM}$ sodium citrate, $\mathrm{pH} 4.0)$ or $1.6 \mathrm{mg} / \mathrm{ml}$ OXT (Bachem, Torrance, CA, USA) for an infusion rate of $4.22 \mu \mathrm{g} / \mathrm{day} / \mathrm{mouse}$. This dose of OXT was determined from previous work in our lab [11]. Mice were anesthetized with isoflurane $(1-3 \%$ in $100 \%$ oxygen) and pumps were implanted subcutaneously in the mid-scapular region. Pump-exchange surgeries were performed once after 6 weeks.

\section{Necropsy}

Mice were sacrificed by $\mathrm{CO}_{2}$ asphyxiation after 8 weeks of treatment (i.e., at 16 weeks of age). Blood was collected by cardiac puncture, transferred to a $1 \mathrm{ml}$ Microvette tube containing EDTA (Sarstedt, Newton, NC, USA) and placed on ice until separation of plasma by centrifugation. Epididymal fat and internal organs were weighed. The fat was snap-frozen in liquid nitrogen or fixed, and frozen samples stored at $-80{ }^{\circ} \mathrm{C}$.

\section{RT-PCR experiments to measure IL- 6 and OXTR mRNA expression}

RT-PCR was used to quantify cellular OXTR, and cytokine mRNA expression levels. Total RNA was isolated using RNeasy extraction kit (Qiagen, Valencia, CA, USA), then cDNA was synthesized after DNase I treatment using reagents from Applied Biosystems (Foster City, CA, USA) following manufacturer's instructions.

Quantitative gene expression of mouse OXTR, IL-6, adiponectin, macrophage marker, F4/80, leptin, and TNF- $\alpha$ by RT-PCR was performed with the TaqMan gene expression assay. The following Applied Biosystems inventoried primers were used: mouse Oxtr (Mm01182684_m1), mouse Il-6 (Mm00446190_m1), mouse adiponectin (Adipoq; Mm00456425_m1), F4/80 (Mm00802529_m1), and Tnf- $\alpha$ (Mm00443260_g1). cDNA (50 ng) were amplified with TaqMan Universal PCR Master Mix and reactions were run using universal cycling conditions on an Applied Biosystems 7500 RealTime PCR system. Samples were analyzed in triplicate. The $\Delta \Delta \mathrm{CT}$ (threshold cycle) method was used to analyze changes in gene expression. Relative quantification (RQ) was expressed as the fold change compared to the appropriate control condition [29]. 18S rRNA was used as the endogenous RNA control. A non-template control was performed to ensure that there was no amplification of genomic DNA.

\section{Western blotting for OXTR}

OXTR protein expression was examined in adipose tissue membrane fractions. Adipose tissue was homogenized in ice-cold lysis buffer $(15 \mathrm{mM} \mathrm{KCl}, 1.5$ $\mathrm{mM} \mathrm{MgCl} 2,10 \mathrm{mM}$ HEPES, $1 \mathrm{mM}$ DTT, protease inhibitors), centrifuged at $1000 \mathrm{x} \mathrm{g}$ for $5 \mathrm{~min}$ at $4{ }^{\circ} \mathrm{C}$, and OXTR enriched membrane fractions in the supernatant were isolated by centrifugation at $100,000 \mathrm{~g} \times 60 \mathrm{~min}$ at $4{ }^{\circ} \mathrm{C}$. The membrane pellet was solubilized in SDS lysis buffer (50 mM Tris, pH 8.6, 1\% SDS). Protein was measured with BCA Protein Assay (Pierce, Rockford, IL, USA). OXTR protein expression was evaluated using previously described methods and using a specific polyclonal anti-rabbit OXTR (cat. no. ab181077; Abcam, Cambridge, MA, USA) validated against tissues from OXTR knockout mice [10]. Immunoreactive bands were detected with appropriate peroxidase conjugated secondary antibody for $1 \mathrm{~h}$ and then visualized with chemiluminescence (Clarity Max substrate, Bio-Rad Laboratories, Hercules, CA, USA). To normalize for protein loading, the membranes were stripped and reprobed with chicken anti-actin antibody (Cat. no. SAB3500350; Sigma, St. Louis, MO) or sodium/potassium ATPase (Cat. no. ab76020; Abcam, Cambridge, MA, USA).

\section{Quantification of adipocyte size}

Formaldehyde-fixed paraffin embedded (FFPE) epididymal fat was sectioned at $4 \mu \mathrm{m}$ and stained with hematoxylin and eosin. Five random fields from each section were imaged at $20 \mathrm{X}$ magnification. Adipocyte size (in $\mu \mathrm{m}^{2}$ ) was measured using the Adiposoft software program [30].

\section{Immunohistochemistry}

FFPE epididymal fat sectioned at $4 \mu \mathrm{m}$ were deparaffinized and antigen retrieval was carried out in TrisEDTA buffer, pH 9.0, using a decloaking chamber. Endogenous peroxidase activity was quenched with $3 \%$ hydrogen peroxide and tissue sections were blocked with rabbit serum, incubated with F4/80 antibody (1100; BioRad, Cat. no., MCA497) or isotype control overnight. After incubation with secondary antibody, sections were exposed to avidin-biotin complex (Vectastain Elite ABC kit, Vector Laboratories, Burlington, CA, USA) then developed using 3,3' -diaminobenzidine (Vector Laboratories; Cat. no., 4100), and counterstained with Gill's Hematoxylin (Vector Laboratories, Cat. no. H-3401).

For each slide, 8 images were captured with a color digital camera and a $10 \mathrm{X}$ objective. Images were processed using the HISTMATCH function of Matlab (MathWorks, Natick, MA, USA) to equalize the color histograms. Adjusted images were then used to quantify the immunoreactive areas with FIJI Image J [31] using color thresholding with the default setting, HSB color space and the same hue, saturation and brightness settings to select the color positive immunoreactive regions 
for all images. F4/80 immunoreactive regions were the average of 8 non-overlapping regions per slide for each tissue and expressed as the \% of total area. Crown-like structures (areas where macrophages surround dying or dead adipocytes) were counted as previously described [6].

\section{Biomarker measurements}

Plasma collected at endpoint was assayed for adiponectin, and serum amyloid A (SAA) using commercially available reagents (R\&D Systems, Minneapolis, MN, USA; Millipore, Billerica, MA: Alpco, Salem, NH, USA, respectively). Plasma oxytocin was measured in unextracted plasma diluted 1:4 using the oxytocin chemiluminescent ELISA kit from Arbor Assay (Ann Arbor, MI, USA). Blood glucose was measured from the tail vein using OneTouch Ultra II glucometer and glucose strips (Lifescan Inc., Malvern, PA, USA).

\section{Lipolysis assay}

Adipocytes were isolated from epididymal fat pads of three or four untreated $\mathrm{db} / \mathrm{db}$ mice (approximately 16 to
20 weeks of age). Tissue was weighed, minced, and digested with collagenase as described above. Isolated adipocytes were incubated at $37^{\circ} \mathrm{C}$ in Krebsbicarbonate-HEPES buffer containing 3\% fatty acid-free bovine serum albumin (Milllipore Sigma, Burlington, MA, USA), $10 \mathrm{mM}$ sodium bicarbonate, $30 \mathrm{mM}$ HEPES, $10 \mathrm{mM}$ glucose and $500 \mathrm{nM}$ adenosine [32] in the presence of OXT (0 to $1000 \mathrm{pM}$ ) and the amount of free fatty acid released in the medium and total triglyceride content of the adipocytes in each incubation were determined with commercial assays (NEFA assay and Triglyceride assay, Sekisui Diagnostics, Exton, PA, USA). Lipolysis was expressed as $\mu \mathrm{mol}$ of free fatty acid per $\mu \mathrm{g}$ of triglyceride.

\section{Statistical analyses}

Data were shown to be normally distributed using the Shapiro-Wilk test and outliers were identified using the ROUT analysis in GraphPad Prism 8. Data are presented as means \pm standard error of the mean (SEM). Results were compared by unpaired independent t-tests or

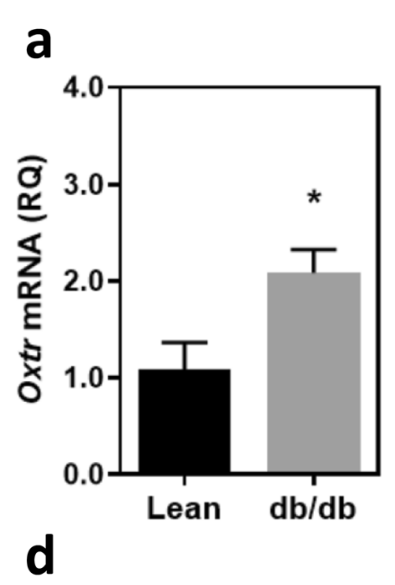

b

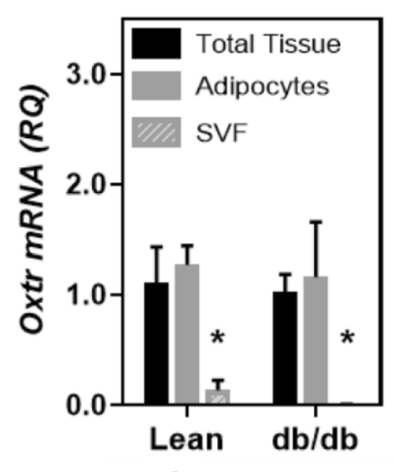

e
C

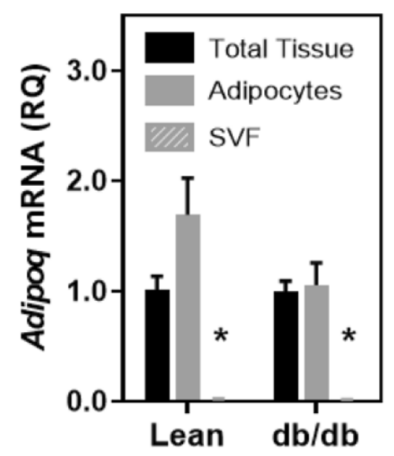

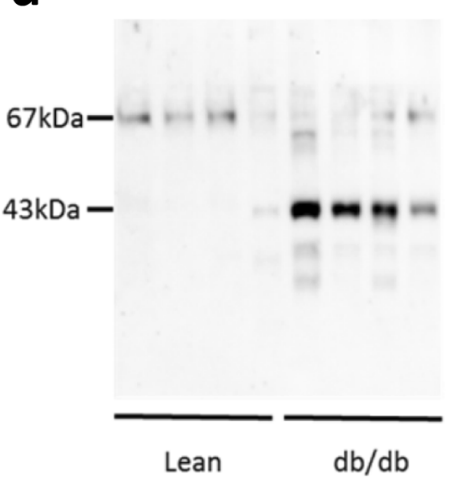

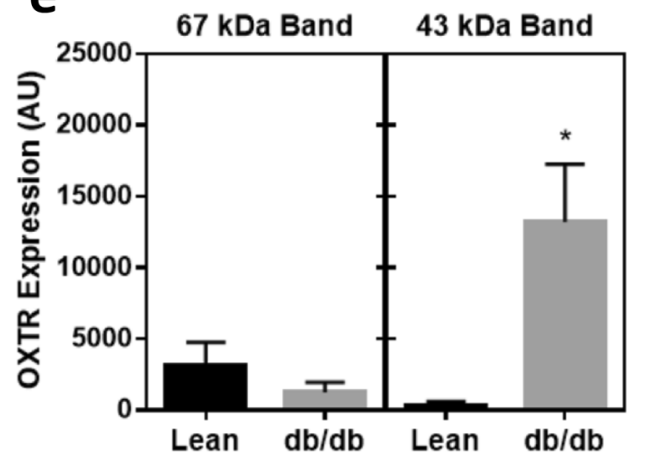

Fig. 1 Obesity modulates OXTR expression in epididymal fat in lean and obese mice. OXTR mRNA expression relative to a control gene, $18 \mathrm{~S}$ rRNA (Panel $\mathbf{a}, n=9$ per group; $p<0.05$ comparing lean and db/db mice), Panels $\mathbf{b}$ and $\mathbf{c}$; Distribution of Oxtr and adiponectin (Adipoq) mRNA, expression in total tissue, adipocyte fraction and stromal vascular fraction (SVF). Data were expressed relative to mRNA level in the total tissue for each respective group ( $n=4$ for lean, $n=4$ for $\mathrm{db} / \mathrm{db}$ ). Oxtr and Adipoq expression were significantly greater in in the adipocyte fraction compared to the SVF fraction (both $p<0.05$ ). Western Blot of OXTR from adipose tissue membrane fractions (Panel d). Molecular weight in kilodaltons $(\mathrm{kDa})$ is indicated on the left. Densitometric quantification of OXTR protein for 67 and $43 \mathrm{kDa}$ bands (Panel e)Data were expressed as mean \pm SEM. * indicates $p<0.05$. 
ANOVA (one or two-way) with post hoc Bonferroni correction. An $\alpha$-level of 0.05 was required for statistical significance.

\section{Results}

Expression of OXTR in adipose tissue

Expression of Oxtr mRNA was evaluated in epididymal fat tissue from lean control and untreated $\mathrm{db} / \mathrm{db}$ mice (Fig. 1a). Compared to lean controls there was a significant increase in Oxtr expression in the obese mice $(p<0.05)$. In order to evaluate the cell types that express Oxtr in adipose tissue, tissue was fractionated to obtain adipocytes and the stromal vascular fraction (SVF; Fig. 1b). In lean and obese mice, the vast majority of Oxtr mRNA expression was significantly greater in the adipocyte fraction compared to the SVF. Expression of adiponectin (Adipoq) mRNA, an adipocyte marker, was evaluated in the fractions to confirm separation of adipocytes from stromal cells (Fig. 1c). Expression of OXTR protein was evaluated in the same tissue (Fig. 1d and e), and was also increased in obese mice relative to controls. As previously shown in other tissues $[10,33]$ two immunoreactive OXTR bands were found in the fat tissue; an unglycosylated $43 \mathrm{kDa}$ form and a mature glycosylated $67 \mathrm{kDa}$ form. In the lean controls the predominant form of the protein was in the $67 \mathrm{kDa}$ band. In the $\mathrm{db} / \mathrm{db}$ mice there was a non-significant decrease in the $67 \mathrm{kDa}$ band relative to the controls, but a dramatic 11-fold increase in the unglycosylated $43 \mathrm{kDa}$ form of the protein.
In vivo infusion of OXT in obese mice

OXT or vehicle was chronically subcutaneously infused via osmotic minipumps in $\mathrm{db} / \mathrm{db}$ mice for 8 weeks. Plasma levels of OXT measured at the study endpoint were $79.4 \pm 14.6$ and $615 \pm 103$ for vehicle and OXT treated mice, respectively $(p<0.001)$. At study endpoint, vehicle control and OXT-treated mice had significantly greater body weight compared with lean controls (both $p<0.001)$, however, there was no significant differences between control and OXT-treated mice $(p=0.07)$. Fasting blood glucose was evaluated during the study and was similar in vehicle and OXT treated $\mathrm{db} / \mathrm{db}$ mice throughout the study and no differences were observed in insulin sensitivity between groups in an insulin tolerance test (Supplemental Data, Figure 1). In addition, by the end of the study OXT-treatment did not affect liver, kidney, pancreas and spleen weights (data not shown). Epididymal fat mass was not different between vehicle control and OXT-treated db/db mice $(p=0.16)$ however, both showed significantly higher epididymal fat weight compared to lean control mice (both $p<0.001$ ) (Fig. 2b). Chronic OXT infusion resulted in a $17 \%$ reduction in visceral adipocyte size ( $p=0.04$; Fig. 3a) in OXT-treated $\mathrm{db} / \mathrm{db}$ mice compared with control $\mathrm{db} / \mathrm{db}$ mice and both of these groups had larger adipocytes compared to the lean controls $(p<0.001)$. Consistent with this observation, in vitro studies from our lab using isolated adipocytes from $\mathrm{db} / \mathrm{db}$ mice demonstrated that OXT can directly activate lipolysis of triglycerides (Fig. 3b). OXT infusion in $\mathrm{db} / \mathrm{db}$ mice also resulted in a significant decrease in visceral fat macrophage infiltration compared to controls, as assessed by immunohistochemistry (Fig.
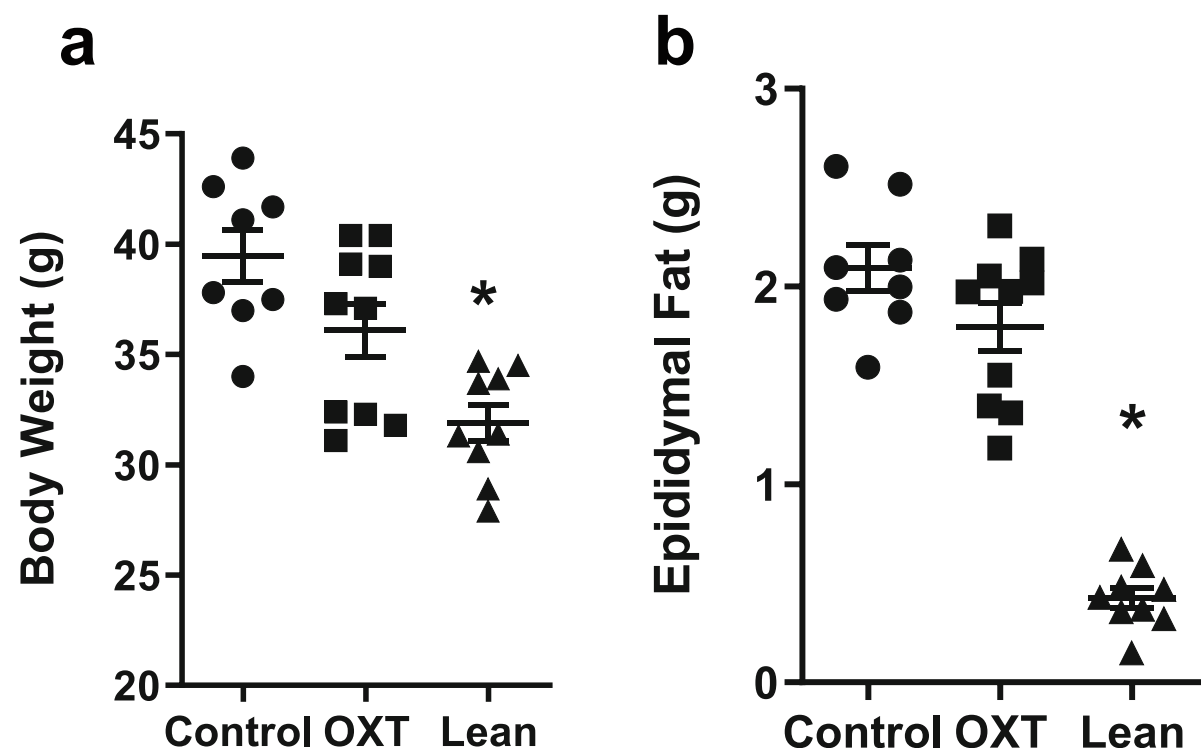

Fig. 2 Body weight (Panel a) and epididymal fat weight (Panel b) in vehicle Control $(n=8)$ or OXT treated $(n=10) \mathrm{db} / \mathrm{db}$ mice after 8 weeks of treatment and in age matched lean control $(n=9)$ mice. Data were expressed as mean \pm SEM. * indicates $p<0.05$ 
a

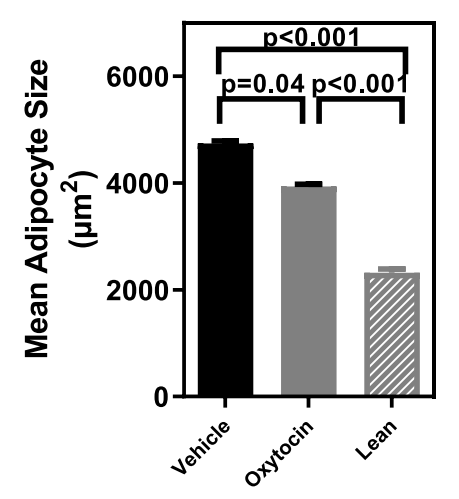

C

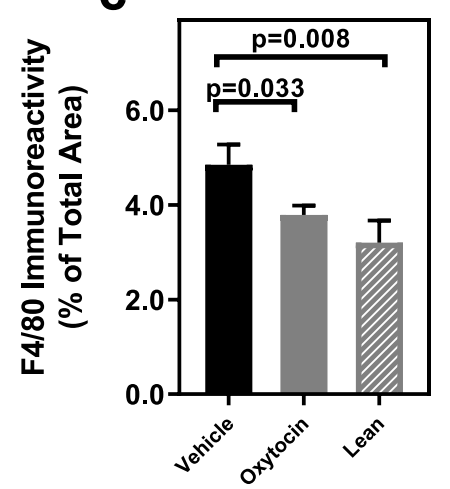

b

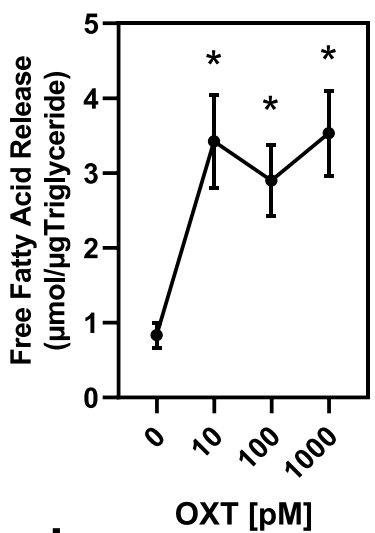

d

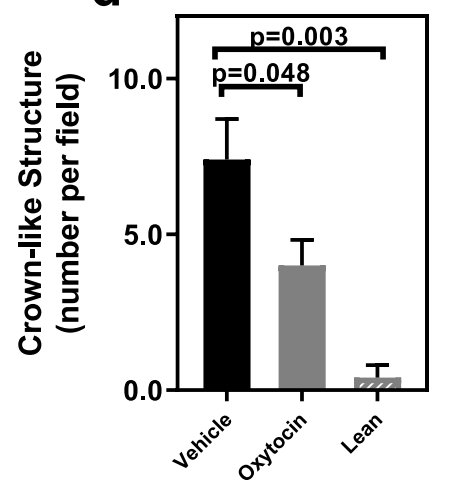

e
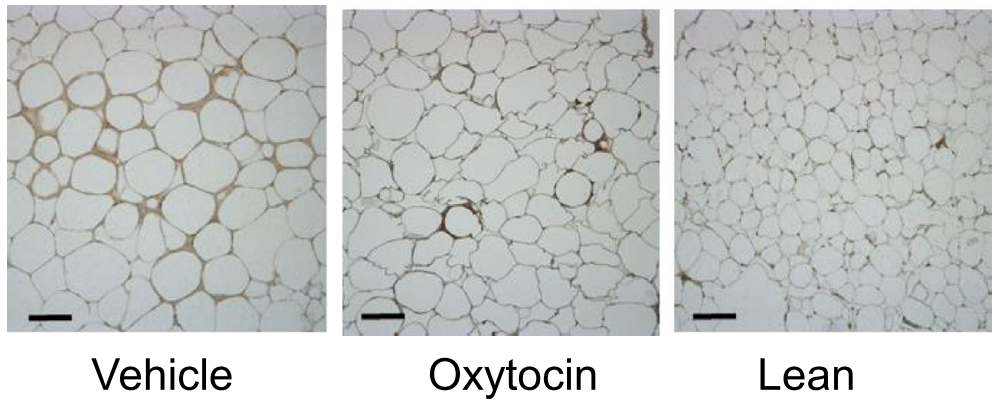

Fig. 3 Effects of OXT infusion on adipocyte size, lipolysis and adipose tissue macrophage infiltration. (Panel a) Adipocyte size in epididymal tissues of Vehicle $(n=8)$ or OXT-treated db/db mice $(n=10)$ and lean control mice $(n=6)$. (Panel $\mathbf{b})$ Lipolysis of triglycerides in isolated adipocytes from $\mathrm{db} / \mathrm{db}$ mice incubated with increasing concentration of OXT for 30 min evaluated by release of free fatty acids. Adipocytes isolated from 3 or 4 mice were pooled and assayed in triplicate at each OXT dose. Data represent the mean for each dose from three separate experiments. OXT significantly increased lipolysis in a dose dependent manner; $p=0.003$ for OXT dose and * indicates $p<0.01$ compared to no oxytocin at all doses by post-hoc analysis(Panel $\mathbf{c})$. Macrophage infiltration into adipose tissue of Vehicle $(n=8)$ or OXT-treated db/db mice $(n=$ 10) and lean control mice $(n=6)$ assessed by immunohistochemistry for F4/80 antigen expression. (Panel d) Densities of crown-like structures in epididymal fat pads of $\mathrm{db} / \mathrm{db}$ mice treated with vehicle $(n=8)$ or OXT $(n=9)$ and lean controls $(n=6)$ expressed as number per microscopic field (average of 5 fields per mouse tissue). (Panel e). Representative photomicrographs of F4/80 immunostained epididymal fat from vehicle and OXT treated $\mathrm{db} / \mathrm{db}$ mice and lean control mice, $\mathrm{bar}=50 \mu \mathrm{m}$. Data were expressed as mean $\pm \mathrm{SEM}$ for each respective group.

3c) and resulted in a decrease of crown-like structures (Fig. 3d, representative images are shown in Fig. 3e).

Given these changes in adipose tissue phenotype, it was hypothesized that OXT infusion would alter adipokine expression, consistent with an anti-inflammatory action. Therefore, adipokine mRNA expression was evaluated in visceral adipose tissue from vehicle and OXTtreated obese mice, as well as lean controls. In general, OXT-treatment in the $\mathrm{db} / \mathrm{db}$ mice shifted the adipokine expression in the direction of the lean controls (Fig. 4a- 
a

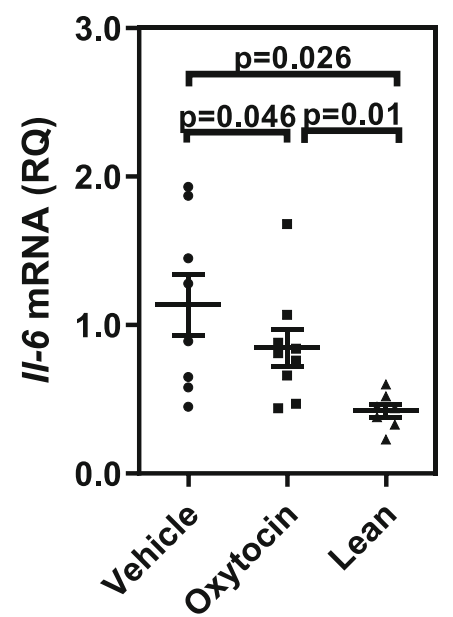

C

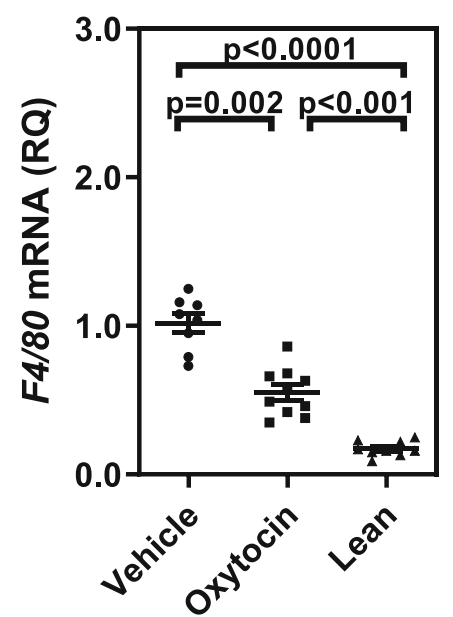

b

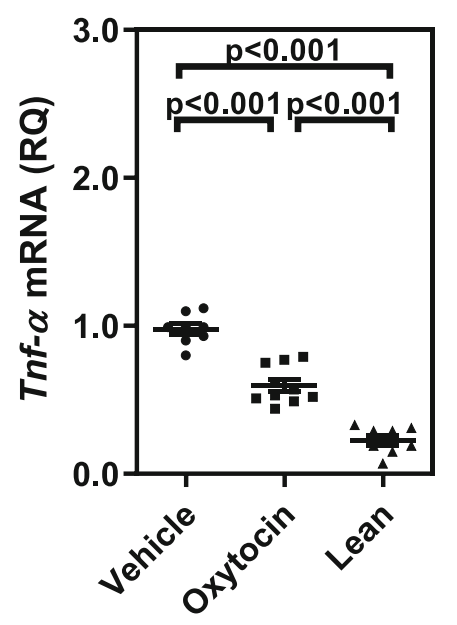

d

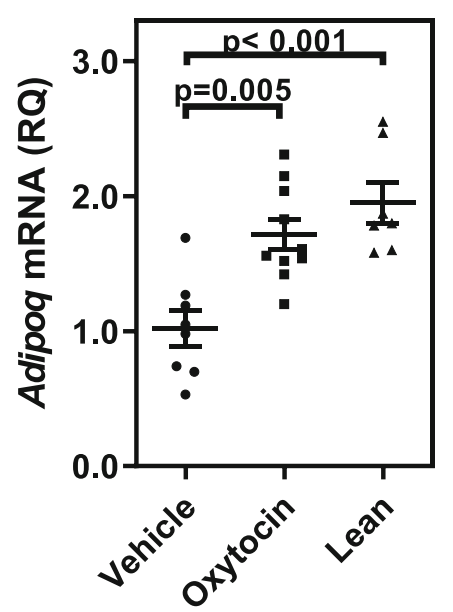

Fig. 4 Adipose tissue mRNA expression of cytokines and adiponectin are altered in oxytocin-treated obese mice compared to vehicle control and lean mice. There was a significant decrease in mRNA expression for IL-6 (Panel a), TNF-a (Panel b), and in the macrophage marker, F4/80 (Panel C) relative to vehicle controls and lean mice. In contrast, oxytocin treatment led to an increase in the mRNA expression of adiponectin (Panel D), an anti-inflammatory adipokine. Data were expressed relative to $18 \mathrm{~S}$ rRNA level for each respective group ( $n=8$ for vehicle, $n=10$ for oxytocintreated, and $n=7$ or 8 for lean)

d). OXT infusion resulted in a significant decrease in mRNA expression of Il-6 (Fig. 4a), Tnf- $\alpha$ (Fig. 4b), and macrophage marker, F4/80 (Fig. 4c) compared to vehicle-controls. The lower F4/80 expression is consistent with the decreased macrophage infiltration observed in Fig. 3c. There was also a significant increase in mRNA expression of the metabolic modulator, adiponectin (Fig. 4d), in visceral fat compared to controls following OXTtreatment.

In addition to visceral fat adipokines, plasma biomarkers related to systemic inflammation were evaluated. In particular, plasma serum amyloid A (SAA) was reduced in $\mathrm{db} / \mathrm{db}$ mice following chronic OXT treatment, and in fact was significantly lower than both the vehicle-control obese mice and lean controls (Fig. 5a). For $\mathrm{db} / \mathrm{db}$ mice, there was a trend for increased plasma adiponectin levels following OXT infusion (Fig. 5b; $p=0.06$ ), which is consistent with the increased adiponectin mRNA expression observed in visceral fat tissue (Fig. 4d).

\section{Discussion}

The major finding of this study is that in an animal model of obesity with hyperglycemia (the $\mathrm{db} / \mathrm{db}$ mouse) chronic OXT treatment led to a reduction in visceral adipose tissue inflammation. Consistent with previously published work [21], OXT infusion reduced adipocyte 

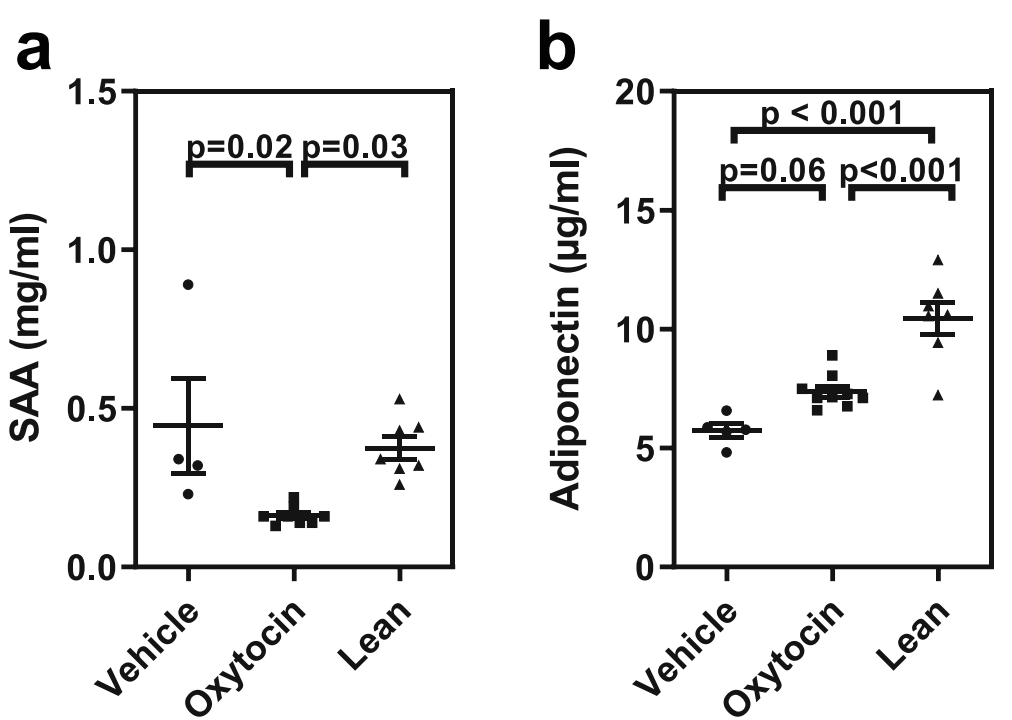

Fig. 5 Oxytocin treatment altered plasma biomarkers of inflammation. (Panel a) Inflammatory biomarker, serum amyloid A (SAA) was attenuated in oxytocin-treated obese mice relative to vehicle controls. (Panel $\mathbf{b})$ There was an increase in the anti-inflammatory plasma marker, adiponectin compared to vehicle controls. Data were expressed as mean \pm SEM for each respective group $(n=4$ for vehicle, $n=9$ for oxytocin-treated, and $n=7$ for lean)

size and macrophage infiltration into adipose tissue. In contrast to the prior study, these changes were observed in the absence of weight loss or alterations in glycemic control, suggesting that OXT works directly to suppress inflammation of adipose tissue rather than through reduction of adipose tissue mass or glycemic control regulation. This notion is further supported by a decrease in crown-like structures, reduced Il- 6 and TNFa mRNA expression, and increased expression of the antiinflammatory adipokine, adiponectin, in the adipose tissue. A possible mechanism by which OXT reduces adipocyte size is suggested by our data and that of others showing that OXT can directly stimulate triglyceride lipolysis $[13,16,17]$. Lastly, plasma SAA levels were decreased and plasma adiponectin levels were increased following OXT infusion, suggesting there was also a decrease in systemic inflammation.

Adipose tissue inflammation characterized by increased cytokine secretion and macrophage infiltration has been associated with obesity. Increased IL- 6 secretion from adipocytes promotes adipose tissue macrophage accumulation [34]. TNF- $\alpha$ secretion from adipose tissue has been associated with insulin resistance that impairs glucose uptake, decreased fatty acid oxidation, increased adipose tissue mass $[35,36]$. A variety of acute-phase response proteins including IL- 6 and TNF- $\alpha$ have been shown to elevate plasma levels of SAA [37, 38]. Circulating levels of SAA are due to increased secretion by the liver, as well as adipocytes in response to inflammation [38] and serves as a stable biomarker of systemic inflammation. A beneficial effect of exogenous
OXT administration may be a direct reduction of these inflammatory cytokine secretions from the adipose tissue thereby reducing macrophage infiltration and SAA protein expression. An additional benefit of OXT treatment is the increased expression of adiponectin, the antiinflammatory effects of adiponectin are also associated with a healthier adipose tissue phenotype [39-41].

Obese $\mathrm{db} / \mathrm{db}$ mice exhibited an increased expression of OXTR mRNA in adipose tissue compared to lean controls, which was previously reported in Zucker rats [42] and ob/ob mice [43]. This observation is consistent with prior work from our lab that demonstrated OXTR is upregulated in response to inflammation in macrophages [10]. These data suggest that activation of the OXTR by its ligand may be important in regulating adipose tissue inflammation and circulating inflammatory cytokines, thereby reducing systemic inflammation that results from obesity.

Two OXTR immunoreactive bands (presumably the Nglycosylated and unglycoslyated forms) were observed in adipose tissue, similar to previous findings in macrophage cells [44] and uterine tissues [45]. Compared to lean controls, obese mice exhibited an increase in adipose tissue OXTR mRNA, and an increase in protein expression associated with the unglycoslyated $43 \mathrm{kDa}$ OXTR band. It is not clear why the two forms of the receptor exist in adipocytes or other cell types. It has been suggested that the glycosylation state of $\mathrm{G}$ protein-coupled receptors (GPCR) could influence transport to the plasma membrane [46]), ligand binding and affinity [33], degradation [47], and the formation of heterodimers with other GPCRs [48-50]. 
Clearly, further studies are needed to understand the functional significance of the two OXTR isoforms.

Previous studies have reported that peripheral OXT infusion significantly reduced body weight gain, adipose tissue mass and improved glycemic control [17-21, 43, 51]. These observations differ from the current study in that OXT infusion reduced adipose tissue inflammation without changes in body weight compared to control mice. These discrepancies could be explained by methodological differences among the studies, including variations among the animal models, OXT dosage, diet composition, duration of treatment, and age of the animals at study onset. For example, studies by Plante et. Al. [21] used the same mouse model but started treatment at an earlier age (4 week old mice compared to 8 week old mice in the current study) and for a longer treatment time ( 12 week vs. 8 week), used a lower OXT dose that increased plasma OXT levels by 2-fold (compared to $\sim 8$-fold) and had a final body weight of $52 \mathrm{~g}$ in the control mice compared to $40 \mathrm{~g}$ in this study. Studies by Altirriba et al. [43] in ob/ob mice showed that OXT treatment over two weeks reduced body weight gain compared to control mice but worsened glucose tolerance. Clearly, OXT treatment of obese mouse models can result in divergent effects. A key variable in the studies mentioned above are OXT dose and route of administration. Plante et al. infused $45 \mathrm{ng} /$ day, Altirribba et al. used $5 \mu \mathrm{g} /$ day and this study gave $4.2 \mu \mathrm{g} /$ day all by continuous infusion. Such divergent doses are likely to affect receptor activity and regulation that may differ depending on the target tissue (reviewed in [52]) that may contribute to the observed differences across studies. Notwithstanding, several studies support the finding that peripheral OXT infusions attenuates adipose tissue and/ or systemic inflammation $[21,43,53]$.

OXT has gained attention as a putative treatment for obesity and type 2 diabetes (T2D) [54-57]. These studies propose that through central and peripheral mechanisms, OXT/OXTR may beneficially regulate glucose metabolism and insulin secretion. Given that systemic inflammation has been associated with the pathophysiology of obesity and T2D [58, 59], the anti-inflammatory actions of OXT/OXTR may also be important in attenuating disease progression.

\section{Study strengths and limitations}

The strength of this study was the demonstration that oxytocin infusion reduced adipose tissue inflammation in an established mouse model of obesity, similar to the effects attributed to oxytocin in a variety of experimental inflammatory conditions [7, 11, 60-63] Limitations of this study include only the use of male mice so that sex differences, if any, were not evaluated. In addition, only a single dose of OXT that was continuously infused subcutaneously was evaluated, thus data on optimal dosage and routes of delivery should be evaluated in future studies. Additionally, given that OXT secretion occurs in a pulsatile manner (e.g., [64, 65]) effects of alternative dosing regimens should also be considered.

\section{Conclusions}

In an animal model of obesity, chronic oxytocin treatment led to a reduction in visceral adipose tissue inflammation and plasma markers of systemic inflammation. The anti-inflammatory effects of OXT were observed in the absence of weight loss or changes in glycemic control, suggesting that OXT works directly to suppress inflammation of adipose tissue rather than through reduction in adipose tissue mass or glycemic regulation. Since obesity has been described as a state of chronic inflammation, dysfunction of the OXT/OXTR system may exacerbate inflammatory diseases/disorders related to obesity such as hypertension, diabetes, and heart disease. Conversely, the anti-inflammatory actions of OXT described in the current study may have utility as a therapeutic treatment to ameliorate some of the deleterious consequences associated with obesity $[44,66]$.

\section{Supplementary information}

Supplementary information accompanies this paper at https://doi.org/10. 1186/s12944-020-01364-X.

Additional file 1: Figure 1S. Fasting blood glucose and insulin tolerance testing in Control and Oxytocin treated $\mathrm{db} / \mathrm{db}$ mice. Table 1S. Obesity modulates OXTR expression in epididymal fat in lean and obese mice.

\section{Abbreviations}

OXT: Oxytocin; OXTR: Oxytocin receptor; db/db: Leptin receptor-deficient mouse; HBSS: Hank's balanced salt solution; SVF: Stromal vascular fraction; PBS: Phosphate-buffered saline; EDTA: Ethylenediaminetetraacetic acid; DTT: Dithiothreitol; SDS: Sodium dodecyl sulfate; FFPE: Formaldehyde-fixed paraffin embedded; RQ: Relative quantification; SAA: Serum amyloid A; TNFa: Tumor necrosis factor; IL-6: Interleukin 6; GPCR: G protein-coupled receptor; T2D: Type 2 diabetes; NEFA: Non-esterified fatty acids; SEM: Standard error of the mean

\section{Acknowledgements}

Not applicable.

\section{Authors' contributions}

PMM and AJM conceptualized the study, participated in data analysis and prepared the manuscript. AS supervised the animal experiments and conducted biochemical assays, curated the data and conducted data analysis. MC performed the animal experiments and conducted biochemical assays and participated in data analysis. RA conducted biochemical assays. The authors read and approved the final manuscript.

\section{Funding}

This work was supported by a Diabetes Research Institute Foundation grant to A.J. Mendez, and National Heart, Lung, and Blood Institute grants HL116387 (P.M. McCabe, P.I.) and HL-04726 (N. Schneiderman, P.I.) and NIH grant 1S100D023579-01 for the VS120 Slide Scanner housed at the University of Miami Miller School of Medicine Analytical Imaging Core Facility. 


\section{Availability of data and materials}

The datasets used and/or analyzed during the current study are available from the corresponding author on reasonable request.

\section{Ethics approval and consent to participate}

Procedures for the care, use and euthanasia of experimental animals followed the protocols and regulations set forth by the Animal Care and Use Committee of the University of Miami and conformed to the Guide for the Care and Use of Laboratory Animals published by the US National Institutes of Health.

\section{Consent for publication}

Not applicable.

\section{Competing interests}

The authors declare they have no competing interests.

\section{Author details}

'Department of Psychology, University of Miami, PO Box 248185, Coral Gables, FL 33124, USA. ²Department of Medicine and Diabetes Research Institute, University of Miami Miller School of Medicine, 1450 N.W. 10th Avenue, Miami, FL 33136, USA.

\section{Received: 20 February 2020 Accepted: 10 August 2020}

\section{Published online: 20 August 2020}

\section{References}

1. Engstrom G, Hedblad B, Stavenow L, Lind P, Janzon L, Lindgarde F. Inflammation-sensitive plasma proteins are associated with future weight gain. Diabetes. 2003;52:2097-101.

2. Hubert HB, Feinleib M, McNamara PM, Castelli WP. Obesity as an independent risk factor for cardiovascular disease: a 26-year follow-up of participants in the Framingham heart study. Circulation. 1983;67:968-77.

3. Coppack SW. Adipose tissue changes in obesity. Biochem Soc Trans. 2005; 33:1049-52.

4. Fruhbeck G. Overview of adipose tissue and its role in obesity and metabolic disorders. Methods Mol Biol. 2008;456:1-22.

5. Kloting N, Bluher M. Adipocyte dysfunction, inflammation and metabolic syndrome. Rev Endocr Metab Disord. 2014;15:277-87.

6. Altintas MM, Rossetti MA, Nayer B, Puig A, Zagallo P, Ortega LM, et al. Apoptosis, mastocytosis, and diminished adipocytokine gene expression accompany reduced epididymal fat mass in long-standing diet-induced obese mice. Lipids Health Dis. 2011;10:198.

7. Detillion CE, Craft TK, Glasper ER, Prendergast BJ, DeVries AC. Social facilitation of wound healing. Psychoneuroendocrinology. 2004;29:1004-11.

8. Iseri SO, Sener G, Saglam B, Gedik N, Ercan F, Yegen BC. Oxytocin protects against sepsis-induced multiple organ damage: role of neutrophils. J Surg Res. 2005;126:73-81.

9. Petersson M, Wiberg U, Lundeberg T, Uvnas-Moberg K. Oxytocin decreases carrageenan induced inflammation in rats. Peptides. 2001;22: $1479-84$.

10. Szeto A, Sun-Suslow N, Mendez AJ, Hernandez RI, Wagner KV, McCabe PM. Regulation of the macrophage oxytocin receptor in response to inflammation. Am J Physiol Endocrinol Metab. 2017;312:E183-e189.

11. Nation DA, Szeto A, Mendez AJ, Brooks LG, Zaias J, Herderick EE, et al. Oxytocin attenuates atherosclerosis and adipose tissue inflammation in socially isolated ApoE-/- mice. Psychosom Med. 2010;72:376-82.

12. Szeto A, Rossetti MA, Mendez AJ, Noller CM, Herderick EE, Gonzales JA, et al. Oxytocin administration attenuates atherosclerosis and inflammation in Watanabe heritable Hyperlipidemic rabbits. Psychoneuroendocrinology. 2013;38:685-93.

13. Yi KJ, So KH, Hata Y, Suzuki Y, Kato D, Watanabe K, et al. The regulation of oxytocin receptor gene expression during adipogenesis. J Neuroendocrinol. 2015;27:335-42

14. Takayanagi Y, Kasahara Y, Onaka T, Takahashi N, Kawada T, Nishimori K. Oxytocin receptor-deficient mice developed late-onset obesity. Neuroreport. 2008;19:951-5.

15. Camerino C. Low sympathetic tone and obese phenotype in oxytocindeficient mice. Obesity (Silver Spring). 2009;17:980-4.

16. Blevins JE, Graham JL, Morton GJ, Bales KL, Schwartz MW, Baskin DG, et al. Chronic oxytocin administration inhibits food intake, increases energy expenditure, and produces weight loss in fructose-fed obese rhesus monkeys. Am J Physiol Regul Integr Comp Physiol. 2015;308:R431-8.

17. Deblon N, Veyrat-Durebex C, Bourgoin L, Caillon A, Bussier AL, Petrosino S, et al. Mechanisms of the anti-obesity effects of oxytocin in diet-induced obese rats. PLoS One. 2011;6:e25565.

18. Maejima Y, Iwasaki Y, Yamahara Y, Kodaira M, Sedbazar U, Yada T. Peripheral oxytocin treatment ameliorates obesity by reducing food intake and visceral fat mass. Aging (Albany NY). 2011;3:1169-77.

19. Morton GJ, Thatcher BS, Reidelberger RD, Ogimoto K, Wolden-Hanson T, Baskin DG, et al. Peripheral oxytocin suppresses food intake and causes weight loss in diet-induced obese rats. Am J Physiol Endocrinol Metab. 2012;302:E134-44.

20. Zhang H, Wu C, Chen Q, Chen X, Xu Z, Wu J, et al. Treatment of obesity and diabetes using oxytocin or analogs in patients and mouse models. PLoS One. 2013;8:e61477.

21. Plante E, Menaouar A, Danalache BA, Yip D, Broderick TL, Chiasson JL, et al. Oxytocin treatment prevents the cardiomyopathy observed in obese diabetic male db/db mice. Endocrinology. 2015;156:1416-28.

22. Xu H, Barnes GT, Yang Q, Tan G, Yang D, Chou CJ, et al. Chronic inflammation in fat plays a crucial role in the development of obesityrelated insulin resistance. J Clin Invest. 2003:112:1821-30.

23. Augustine KA, Rossi RM. Rodent mutant models of obesity and their correlations to human obesity. Anat Rec. 1999;257:64-72.

24. Speakman J, Hambly C, Mitchell S, Król E. The contribution of animal models to the study of obesity. Lab Anim. 2008:42:413-32.

25. Speakman JR. Use of high-fat diets to study rodent obesity as a model of human obesity. Int J Obes (Lond). 2019:43:1491-2.

26. Lee S-e, I-s J, J-s P, Lee J-H, Lee S-Y, S-y B, et al. Systemic immunity of obese-diabetes model (db/db) mice. Mol Cellular Toxicol. 2010;6:143-9.

27. Yamakawa T, Tanaka S-I, Yamakawa Y, Kiuchi Y, Isoda F, Kawamoto S, et al, Augmented production of tumor necrosis factor-a in obese mice. Clin Immunol Immunopathol. 1995;75:51-6.

28. An SM, Kim SS, Kim J, Park MN, Lee JE, Cho SK, et al. Expression of reproductive hormone receptors and contractionassociated genes in porcine uterus during the estrous cycle. Mol Med Rep. 2017;15:4176-84.

29. Schmittgen TD, Livak KJ. Analyzing real-time PCR data by the comparative C(T) method. Nat Protoc. 2008;3:1101-8.

30. Galarraga M, Campion J, Munoz-Barrutia A, Boque N, Moreno H, Martinez JA, et al. Adiposoft: automated software for the analysis of white adipose tissue cellularity in histological sections. J Lipid Res. 2012;53:2791-6.

31. Schindelin J, Arganda-Carreras I, Frise E, Kaynig V, Longair M, Pietzsch T, et al. Fiji: an open-source platform for biological-image analysis. Nat Methods. 2012;9:676-82

32. Holm C, Olivecrona G, Ottosson M. Assays of Lipolytic enzymes. In: Ailhaud G, editor. Adipose tissue protocols. Totowa: Springer New York; 2001. p. 97119.

33. Kimura $T$, Makino $Y$, Bathgate $R$, Ivell $R$, Nobunaga $T$, Kubota $Y$, et al. The role of N-terminal glycosylation in the human oxytocin receptor. Mol Hum Reprod. 1997:3:957-63.

34. Mauer J, Denson JL, Brüning JC. Versatile functions for IL-6 in metabolism and cancer. Trends Immunol. 2015:36:92-101.

35. Akash MSH, Rehman K, Liaqat A. Tumor necrosis factor-alpha: role in development of insulin resistance and pathogenesis of type 2 diabetes mellitus. J Cell Biochem. 2018;119:105-10.

36. Makki K, Froguel P, Wolowczuk I. Adipose tissue in obesity-related inflammation and insulin resistance: cells, cytokines, and chemokines. ISRN inflammation. 2013;2013:139239.

37. De Buck M, Gouwy M, Wang JM, Van Snick J, Proost P, Struyf S, et al. The cytokine-serum amyloid A-chemokine network. Cytokine Growth Factor Rev. 2016;30:55-69.

38. den Hartigh LJ, Wang S, Goodspeed L, Ding Y, Averill M, Subramanian S, et al. Deletion of serum amyloid A3 improves high fat high sucrose dietinduced adipose tissue inflammation and hyperlipidemia in female mice. PLoS One. 2014:9:e108564

39. Bruun JM, Lihn AS, Verdich C, Pedersen SB, Toubro S, Astrup A, et al. Regulation of adiponectin by adipose tissue-derived cytokines: in vivo and in vitro investigations in humans. Am J Physiol Endocrinol Metab. 2003;285: E527-33.

40. Nigro E, Scudiero O, Monaco ML, Palmieri A, Mazzarella G, Costagliola C, et al. New insight into adiponectin role in obesity and obesity-related diseases. Biomed Res Int. 2014;2014:658913. 
41. Ouchi N, Walsh K. Adiponectin as an anti-inflammatory factor. Clin Chim Acta. 2007;380:24-30.

42. Gajdosechova L, Krskova K, Olszanecki R, Zorad S. Differential regulation of oxytocin receptor in various adipose tissue depots and skeletal muscle types in obese Zucker rats. Horm Metab Res. 2015;47:600-4.

43. Altirriba J, Poher AL, Caillon A, Arsenijevic D, Veyrat-Durebex C, Lyautey J, et al. Divergent effects of oxytocin treatment of obese diabetic mice on adiposity and diabetes. Endocrinology. 2014;155:4189-201.

44. Chaves VE, Tilelli CQ, Brito NA, Brito MN. Role of oxytocin in energy metabolism. Peptides. 2013:45:9-14.

45. Kojro E, Hackenberg M, Zsigo J, Fahrenholz F. Identification and enzymatic deglycosylation of the myometrial oxytocin receptor using a radioiodinated photoreactive antagonist. J Biol Chem. 1991;266:21416-21.

46. Dong C, Filipeanu CM, Duvernay MT, Wu G. Regulation of G proteincoupled receptor export trafficking. Biochim Biophys Acta Biomembr. 2007; 1768:853-70.

47. Goth CK, Petäjä-Repo UE, Rosenkilde MM. G protein-coupled receptors in the sweet spot: glycosylation and other post-translational modifications. ACS Pharmacol Transl Sci. 2020;3:237-45.

48. Romero-Fernandez W, Borroto-Escuela DO, Agnati LF, Fuxe K. Evidence for the existence of dopamine d2-oxytocin receptor heteromers in the ventral and dorsal striatum with facilitatory receptor-receptor interactions. Mol Psychiatry. 2013;18:849-50.

49. Terrillon S, Durroux T, Mouillac B, Breit A, Ayoub MA, Taulan M, et al. Oxytocin and vasopressin V1a and V2 receptors form constitutive homoand heterodimers during biosynthesis. Mol Endocrinol. 2003;17:677-91.

50. Wrzal PK, Goupil E, Laporte SA, Hébert TE, Zingg HH. Functional interactions between the oxytocin receptor and the $\beta 2$-adrenergic receptor: implications for ERK1/2 activation in human myometrial cells. Cell Signal. 2012;24:333-41.

51. Iwasaki Y, Maejima Y, Suyama S, Yoshida M, Arai T, Katsurada K, et al. Peripheral oxytocin activates vagal afferent neurons to suppress feeding in normal and leptin-resistant mice: a route for ameliorating hyperphagia and obesity. Am J Physiol Regul Integr Comp Physiol. 2015;308:R360-9.

52. Kimura T, Saji F, Nishimori K, Ogita K, Nakamura H, Koyama M, et al. Molecular regulation of the oxytocin receptor in peripheral organs. J Mol Endocrinol. 2003:30:109-15.

53. Garrido-Urbani S, Deblon N, Poher AL, Caillon A, Ropraz P, RohnerJeanrenaud $F$, et al. Inhibitory role of oxytocin on TNFa expression assessed in vitro and in vivo. Diabetes Metab. 2018;44:292-5.

54. Barengolts E. Oxytocin - an emerging treatment for obesity and dysglycemia: review of randomized controlled trials and cohort studies. Endocr Pract. 2016;22:885-94.

55. Blevins JE, Baskin DG. Translational and therapeutic potential of oxytocin as an anti-obesity strategy: insights from rodents, nonhuman primates and humans. Physiol Behav. 2015;152:438-49.

56. Cai D, Purkayastha S. A new horizon: oxytocin as a novel therapeutic option for obesity and diabetes. Drug Discovery Today: Disease Mechanisms. 2013; 10:e63-8.

57. Olszewski PK, Klockars A, Levine AS. Oxytocin and potential benefits for obesity treatment. Curr Opin Endocrinol Diabetes Obes. 2017;24:320-5.

58. Donath MY. Targeting inflammation in the treatment of type 2 diabetes: time to start. Nat Rev Drug Discov. 2014;13:465-76.

59. Wang $X$, Bao W, Liu J, Ouyang YY, Wang D, Rong S, et al. Inflammatory markers and risk of type 2 diabetes: a systematic review and meta-analysis. Diabetes Care. 2013:36:166-75.

60. Biyikli NK, Tugtepe H, Sener G, Velioglu-Ogunc A, Cetinel S, Midillioglu S, et al. Oxytocin alleviates oxidative renal injury in pyelonephritic rats via a neutrophil-dependent mechanism. Peptides. 2006;27:2249-57.

61. Iseri SO, Sener G, Saglam B, Gedik N, Ercan F, Yegen BC. Oxytocin ameliorates oxidative colonic inflammation by a neutrophil-dependent mechanism. Peptides. 2005;26:483-91.

62. Klein BY, Tamir H, Hirschberg DL, Ludwig RJ, Glickstein SB, Myers MM, et al. Oxytocin opposes effects of bacterial endotoxin on ER-stress signaling in Caco2BB gut cells. Biochim Biophys Acta Gen Subj. 2016;1860:402-11.

63. Welch MG, Margolis KG, Li Z, Gershon MD. Oxytocin regulates gastrointestinal motility, inflammation, macromolecular permeability, and mucosal maintenance in mice. Am J Physiol Gastrointest Liver Physiol. 2014; 307:G848-62.

64. Baskaran C, Plessow F, Silva L, Asanza E, Marengi D, Eddy KT, et al. Oxytocin secretion is pulsatile in men and is related to social-emotional functioning. Psychoneuroendocrinology. 2017;85:28-34.
65. Lincoln DW. Dynamics of oxytocin secretion. In: Knowles F, Vollrath L, editors. Neurosecretion - The Final Neuroendocrine Pathway: VI International Symposium on Neurosecretion, London 1973. Berlin: Springer Berlin Heidelberg; 1974. p. 129-33.

66. Cai D, Purkayastha S. A new horizon: oxytocin as a novel therapeutic option for obesity and diabetes. Drug Discov Today Dis Mech. 2013;10:e63-8.

\section{Publisher's Note}

Springer Nature remains neutral with regard to jurisdictional claims in published maps and institutional affiliations.

\section{Ready to submit your research? Choose BMC and benefit from:}

- fast, convenient online submission

- thorough peer review by experienced researchers in your field

- rapid publication on acceptance

- support for research data, including large and complex data types

- gold Open Access which fosters wider collaboration and increased citations

- maximum visibility for your research: over $100 \mathrm{M}$ website views per year

At BMC, research is always in progress.

Learn more biomedcentral.com/submissions 